\title{
INFLUENCE OF VASOPRESSIN ON THE METABOLIC RATE IN RATS
}

\author{
Morio Tsukada, Akimasa OKuno \\ AND Shinji ITOH \\ Department of Physiology, Hokkaido University \\ School of Medicine, Sapporo
}

Our previous study ${ }^{1)}$ demonstrated a marked fall in the body temperature following the administration of vasopressin in rats. Since vasopressin causes a remarkable constriction of the cutaneous vessels, dissipation of the body heat through the skin will not be increased by this hormone. Therefore the fall in the body temperature should be attributed to a decrease in the heat production. The present investigation was carried out to verify this inference, observing changes in the metabolic rate in response to vasopressin in rats.

\section{METHODS}

Male Wistar rats, weighing approximately $200 \mathrm{~g}$, were used throughout the experiments. Metabolic rates were measured by an open circuit method, using a glass chamber, $370 \mathrm{ml}$ in capacity, through which air was drawn at a rate of approximately $1,300 \mathrm{ml}$ per 10 minutes. The volume of effluent air was measured and the $\mathrm{O}_{2} \%$ and $\mathrm{CO}_{2} \%$ determined with a Scholander gas analysis apparatus; the oxygen consumption and carbon dioxide production were calculated and expressed as $\mathrm{ml}$ per $100 \mathrm{~cm}^{2}$ per 10 minutes.

Synthetic lysine vasopressin (Sandoz) and synthetic oxytocin (Syntocinon; Sandoz), diluted with physiological saline, were injected intraperitoneally and DL-norepinephrine subcutaneously.

Alloxan diabetes was produced by the intravenous injection of $7.5 \mathrm{mg}$ alloxan monohydrate per $100 \mathrm{~g}$ body weight into rats which had been fasted 48 hours. The rats, 48 hours following alloxan injection, were used if fasting blood sugars were greater than $200 \mathrm{mg}$ per $100 \mathrm{ml}$ of blood.

\section{RESULTS}

1. Effect of vasopressin on the oxygen consumption in fasted rats. Lysine vasopressin was injected in doses of $100 \mathrm{mU}$ and $40 \mathrm{mU}$ per $100 \mathrm{~g}$ body weight intraperitoneally into rats which had been fasted for about 24 hours prior to the experiment. Collection of expired air was made during 10-minute period

Received for publication February 25, 1965

塚田守雄, 奥野晃正, 伊藤真次 
TABLE 1.

Changes in the oxygen consumption and carbon dioxide production following the administration of lysine vasopressin, oxytocin and hypertonic sodium chloride solutions.

\begin{tabular}{|c|c|c|c|c|}
\hline Group & $\begin{array}{l}\text { No. of } \\
\text { rats }\end{array}$ & $\begin{array}{c}\mathrm{O}_{2} \\
\text { per } 100 \mathrm{~cm}^{2}\end{array}$ & $\begin{array}{l}\mathrm{CO}_{2} \\
\text { per } 100 \mathrm{~cm}^{2}\end{array}$ & $\mathrm{RQ}$ \\
\hline Control & 10 & $20.6 \pm 0.48^{*}$ & $14.4 \pm 0.44$ & $.703 \pm .013$ \\
\hline $\begin{array}{l}\text { Vasopressin } \\
100 \mathrm{mU}\end{array}$ & 13 & $\begin{array}{c}13.3 \pm 0.70 \\
\mathrm{P}<0.001\end{array}$ & $\begin{array}{l}9.7 \pm 0.44 \\
\mathrm{P}<0.001\end{array}$ & $.734 \underset{\mathrm{NS}}{ \pm .015}$ \\
\hline $40 \mathrm{mU}$ & 8 & $\begin{array}{c}14.7 \pm 0.76 \\
\mathrm{P}<0.001\end{array}$ & $\begin{array}{c}10.7 \pm 0.40 \\
\mathrm{P}<0.001\end{array}$ & $\frac{736 \pm .021}{\mathrm{NS}}$ \\
\hline $10 \mathrm{mU}$ & 10 & 19. $0 \underset{\mathrm{NS}}{ \pm} 1.16$ & $13.3 \underset{\mathrm{NS}}{ \pm} 0.79$ & $\frac{.702 \pm .010}{\mathrm{NS}}$ \\
\hline $\begin{array}{r}\text { Oxytocin } \\
400 \mathrm{mU}\end{array}$ & 9 & 19. $\underset{\mathrm{NS}}{\mathrm{N}} \mathbf{\pm 0 . 2 5}$ & 13. $\underset{\mathrm{NS}}{8 \pm 0.17}$ & $.709 \pm .010$ \\
\hline $10 \% \mathrm{NaCl}, 2 \mathrm{ml}$ & 10 & $\begin{array}{c}16.7 \pm 0.94 \\
P<0.01\end{array}$ & $\begin{array}{c}11.6 \pm 0.63 \\
\mathrm{P}<0.01\end{array}$ & $.697 \underset{\mathrm{NS}}{ \pm .010}$ \\
\hline $2 \% \mathrm{NaCl}, 7$ days & 10 & $19.6 \underset{\mathrm{NS}}{6 \pm 0.94}$ & 13. $\frac{8 \pm 0.67}{\mathrm{NS}}$ & $.702 \pm .027$ \\
\hline
\end{tabular}

* Mean \pm S. E.

between 20 and 30 minutes after the injection. As shown in TABLE 1, the administration of vasopressin caused marked decreases in the oxygen consumption and carbon dioxide production. The reduction of oxygen consumption was as much as 35.4 per cent after $100 \mathrm{mU}$ vasopressin and 28.6 per cent after $40 \mathrm{mU}$ on averages. Injection of the hormone in a dose of $10 \mathrm{mU}$ was however ineffective in causing a decrease in the metabolic rate and oxytocin in a dose of $400 \mathrm{mU}$ also failed to produce any change in it.

In these fasted rats $R Q$ values were considerably low, averaging 0.703 in the control group. After administration of $100 \mathrm{mU}$ vasopressin the average value increased to 0.734 and after $40 \mathrm{mU}$ to 0.736 , though the changes were not statistically significant.

2. Effect of hypertonic saline on the oxygen consumption in fasted rats. Not only exogenous but endogenous vasopressin may also bring about the decrease in the oxygen consumption. To know the effect of endogenous hormone, 10 per cent sodium chloride solution was administered in a dose of $2 \mathrm{ml}$ per $100 \mathrm{~g}$ body weight through a stomach tube. Expired air collected during 10-minute period between 25 to 35 minutes after the administration was analyzed for the oxygen and carbon dioxide. Results indicated a slight but statistically significant decrease in the metabolic rate (TABLE 1 ).

Effect of chronic administration of 2 per cent sodium chloride solution for 

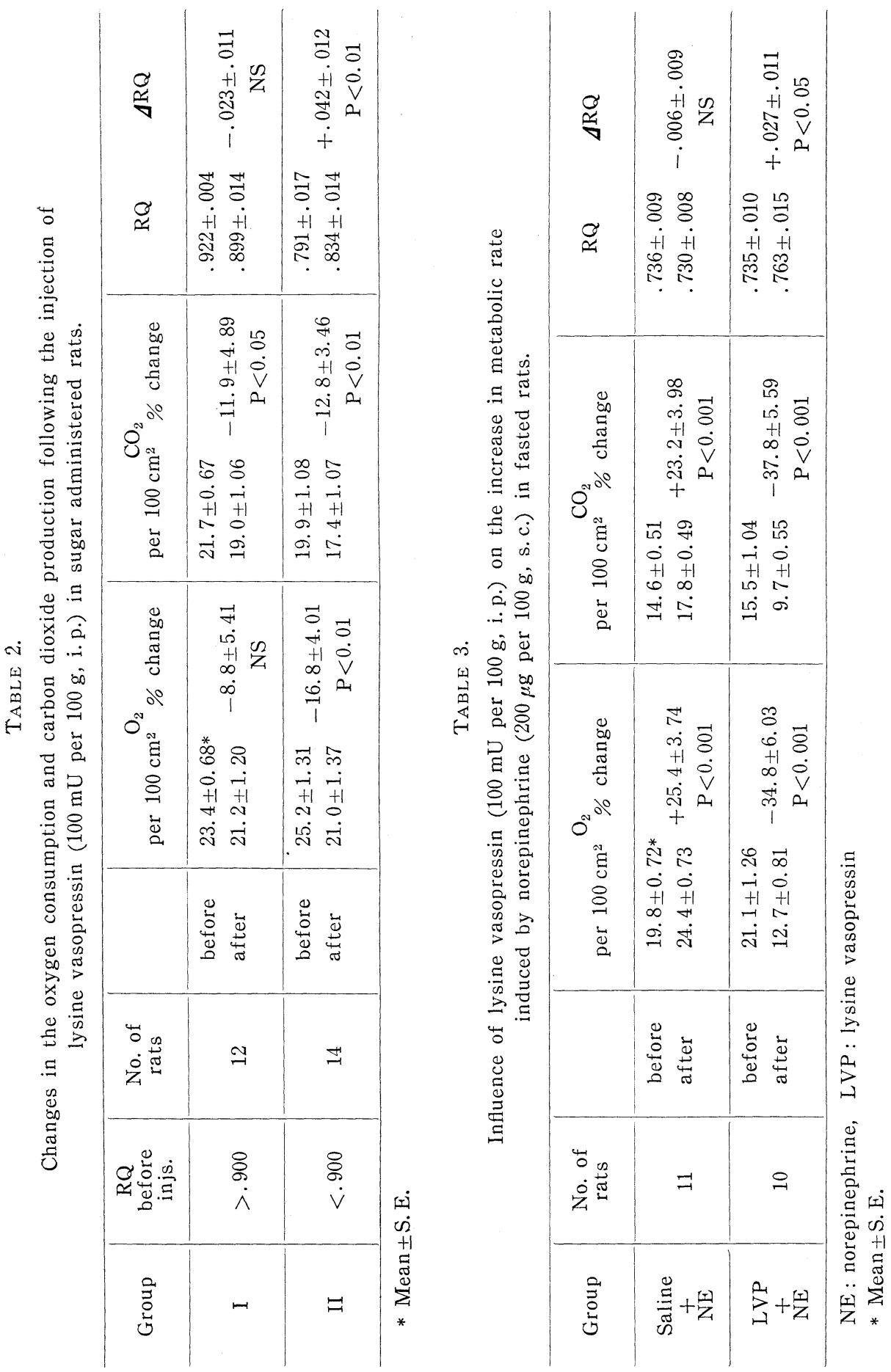
7 days as drinking fluid in place of tap water was also examined, but no significant change in the metabolic rate was resulted by this treatment. (TABLE 1).

3. Relation between changes in the oxygen consumption and respiratory quotient produced by vasopressin in sugar administered rats. In fasted animals the RQs were too low to evaluate its change which might be produced by vasopressin. Therefore in this series of experiments 10 per cent sugar solution was given ad libitum for about 24 hours prior to the experiment without giving any food. Expired air was collected before and after (from 20 to 30 minutes) the injection of vasopressin. As expected, sugar administration caused an increase in the RQs, though the extent of increase was variable. In general the response to vasopressin was less in extent in rats which showed high RQ values than those with rather low RQs. For convenience results were divided into two groups according to the RQs either higher than 0.900 or less than this level.

In rats with high $R Q$ values (Group I in TABLE 2) intraperitoneal injection of $100 \mathrm{mU}$ vasopressin did not cause any significant change in the oxygen consumption, though a slight decrease in the carbon dioxide production was observed. On the other hand, in rats with low RQ values (Group II in TABLE 2) administration of the same amount of vasopressin resulted in a significant decrease in the metabolic rate as shown in the table. However, the extent of decrease was considerably less than those observed in the fasted animals. It was interesting that the decrease in the oxygen consumption was associated with an elevation of the RQs. If the changes in the oxygen consumption were plotted against those in the RQs, as shown in FIG. 1, a significant negative correlation was found.

4. Influence of vasopressin on the increase in oxygen consumption provoked by norepinephrine in fasted rats. The calorigenic action of norepinephrine has been shown to be related to its ability to increase the rate of free fatty acid (FFA) mobilization. This may indicate that norepinephrine stimulates the utilization of either FFA or triglycerides ${ }^{2}$. If we presume a possibility that vasopressin may inhibit the fat metabolism, the increase in metabolic rate following norepinephrine may be diminished by this hormone.

In the present experiment, after collecting control samples of expired air, vasopressin was injected in experimental group of rats and the same amount of physiological saline in control ones. Fifteen minutes thereafter norepinephrine was subcutaneously injected in a dose of $200 \mu \mathrm{g}$ per $100 \mathrm{~g}$, and 5 minutes later the second gas sumples were started to be collected.

As shown in TABLE 3, norepinephrine caused a significant increase in the metabolic rate, while in vasopressin treated rats the effect of norepinephrine was entirely abolished. The values in the latter group were at the same low 


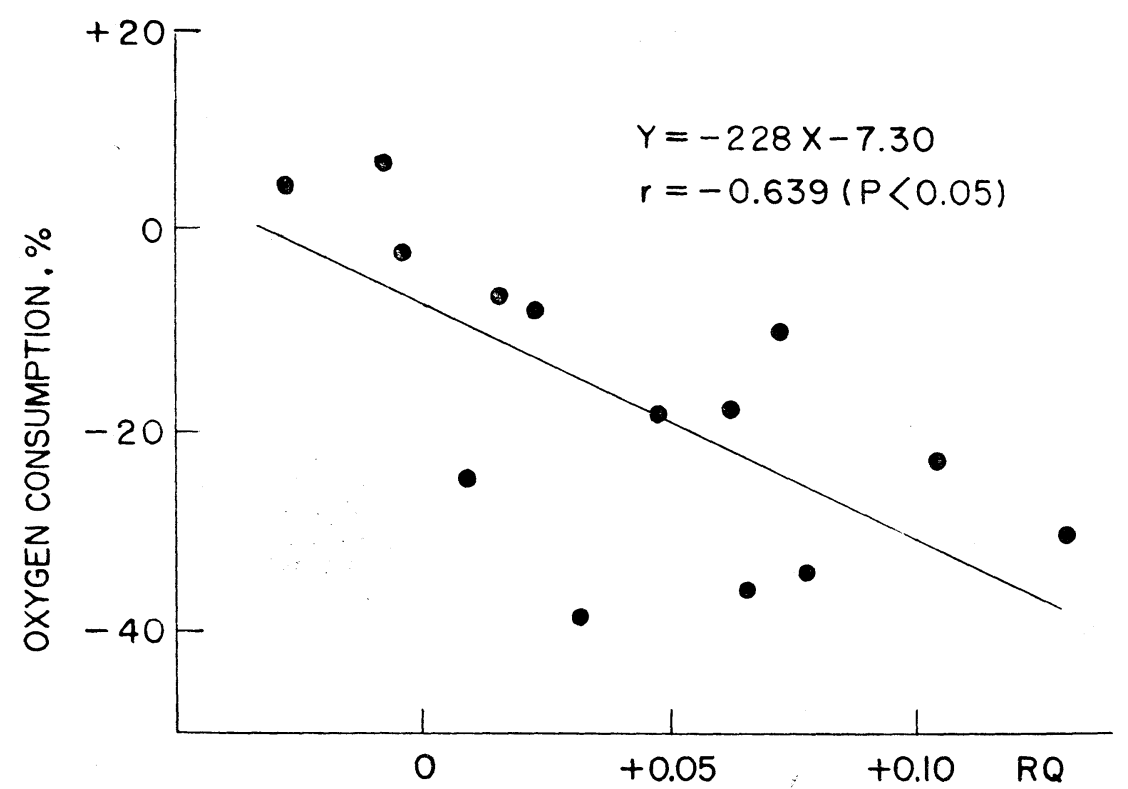

FIG. 1. Relation between changes in oxygen consumption and respiratory quotients following vasopressin injection in sugar administered rats (Group II in TABLE 2).

level as observed in rats injected with vasopressin alone (TABLE 1).

5. Effect of vasopressin on the oxygen consumption in alloxan diabetic rats. Assuming again that vasopressin may affect the utilization of fat, the effect of this hormone was examined in alloxan diabetic rats in which fat was considered to be preferentially used as energy substrate. Expectation was that the suppressive effect of the hormone on the oxygen consumption could be pronounced under the condition used.

In alloxan diabetic rats the metabolic rate was extremely low by an average of 64 per cent of control level and only slight decrease was resulted from vasopressin administration. However, the change was statistically significant (TABLE 4).

\section{DISCUSSION}

Following the administration of vasopressin a marked decrease in the metabolic rate was found in fasted rats. A prompt fall of the body temperature induced by vasopressin ${ }^{11}$ will be attributed mainly to the reduced metabolic rate. The effect of vasopressin was particularly marked in fasted rats in which the RQs were considerably low. On the other hand, in rats given sugar solution the effect was less. It is interesting that a significant negative correlation was found between decrease in the oxygen consumption and elevation 
of the RQ. The observed increase in the RQ may not necessarily indicate an increase in the oxidation of carbohydrate but rather a decrease in fat utilization, since the total energy output was markedly reduced.

In order to know the proportion of fat and carbohydrate oxidation a calculation was made, assuming that 15 per cent of the total oxygen consumption was due to protein metabolism and that the protein metabolism was not affected by vasopressin. The latter assumption may require further proof. However, there may not be serious error even if the protein metabolism is affected by the hormone, because the oxidation of protein contributes relatively small part of the total oxygen consumption. As shown in FIG. 2, the oxidation of fat was found to be significantly reduced from $15.7 \mathrm{ml}$ per $100 \mathrm{~cm}^{2}$ per $10 \mathrm{~min}$ to $9.5 \mathrm{ml}$ after injection of vasopressin, while that of carbohydrate increased to some extent.

The suppressive effect of vasopressin was not observed in rats with high $R Q$ values in which carbohydrate might be the major fuel for the energy output. This fact suggests that vasopressin does not suppress the utilization of carbohydrate. The inference may be supported by the evidence that vasopressin possesses a glycogenolytic potency ${ }^{3,4)}$ and elevates the blood glucose level ${ }^{5}$.

It has been reported by MIRSKY, ${ }^{6,7}$ that the injection of vasopressin as well as oxytocin caused a significant decrease in the concentration of plasma FFA in dogs. Our unpublished data

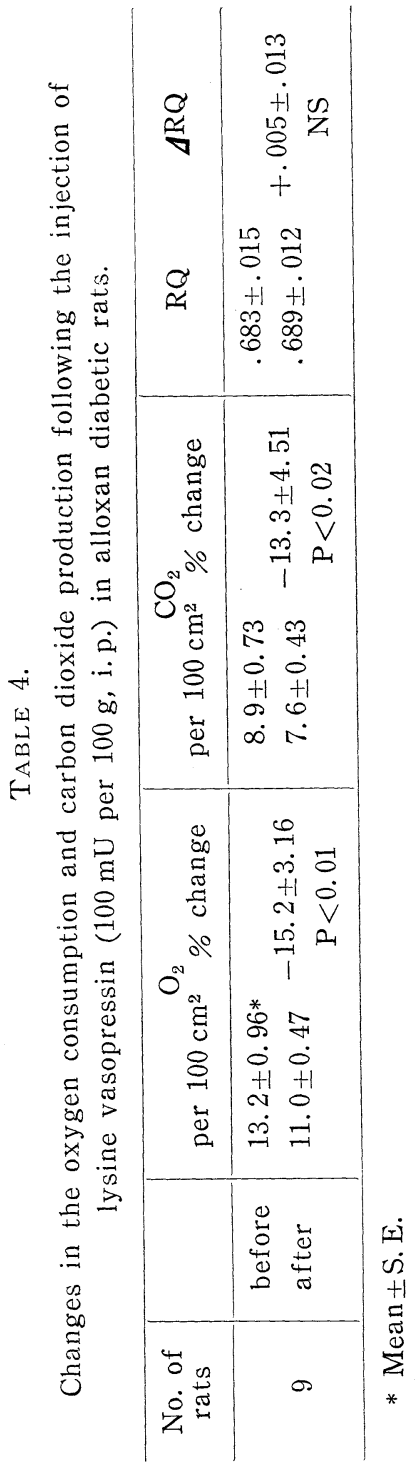
in rats are in accord with MIRSKY's observations. However, the decrease in the plasma FFA may not be an essential mechanism for possible reduction of the fat metabolism due to vasopressin, since oxytocin which is effective to cause a marked decrease in the plasma FFA did not affect the metabolic rate at all.

Since ThIBAULT ${ }^{8)}$ found the calorigenic effect of norepinephrine, the increase in oxygen consumption caused by the catecholamine has been extensively studied in animals and in man. It has become evident that one of the most striking effects of the catecholamines is their ability to stimulate mobilization 


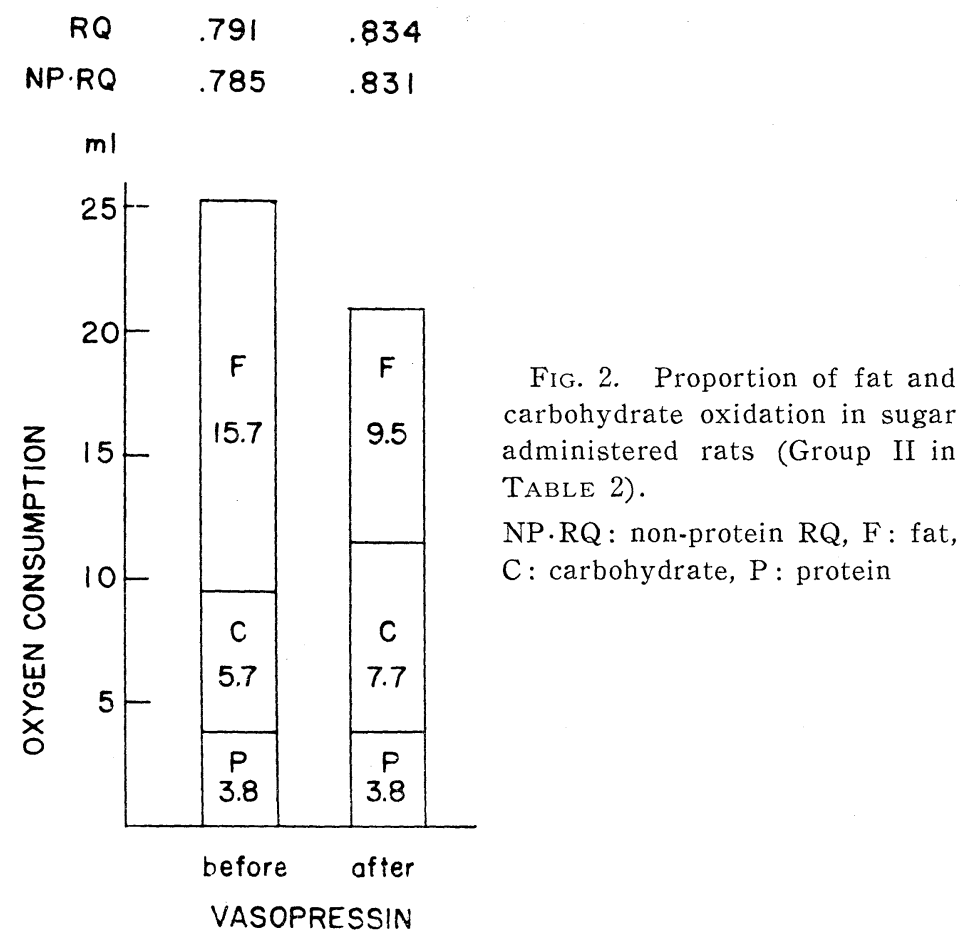

of depot fat in the form of $\mathrm{FFA}^{9)}$. The calorigenic action of norepinephrine is related to the potency to increase the rate of FFA mobilization ${ }^{2}$ and the action is thought to be primarily supported by the oxidation of $\mathrm{FFA}^{10)}$. If vasopressin suppresses the utilization of fat as metabolic fuel, the calorigenic effect of norepinephrine will be reduced by treatment with this hormone. A complete abolishment of the norepinephrine effect was shown in animals injected with vasopressin in this experiment. To know the proportion of fat oxidation in the total oxygen consumption in these animals, similar calculations to the above were made (FIG. 3). The oxygen consumption due to fat oxidation was found to increase from $15.7 \mathrm{ml}$ per $100 \mathrm{~cm}^{2}$ per $10 \mathrm{~min}$ to $20.8 \mathrm{ml}$ following norepinephrine injection in control group, while in vasopressin treated rats it decreased to $8.2 \mathrm{ml}$, that is only 39 per cent of the above figure.

It is also well known that fat is the main fuel in diabetic animals which can not utilize carbohydrate. In alloxan diabetic rats vasopressin is expected to exhibit its effect in decreasing fat metabolism. Though in these animals the metabolic rate was extremely low by an average of 64 per cent of control level, a significant difference in the oxygen consumption was observed between the values before and after vasopressin injection.

After all, the present experiments strongly suggest that the injection of vasopressin causes a marked decrease in the metabolic rate by its suppressive 

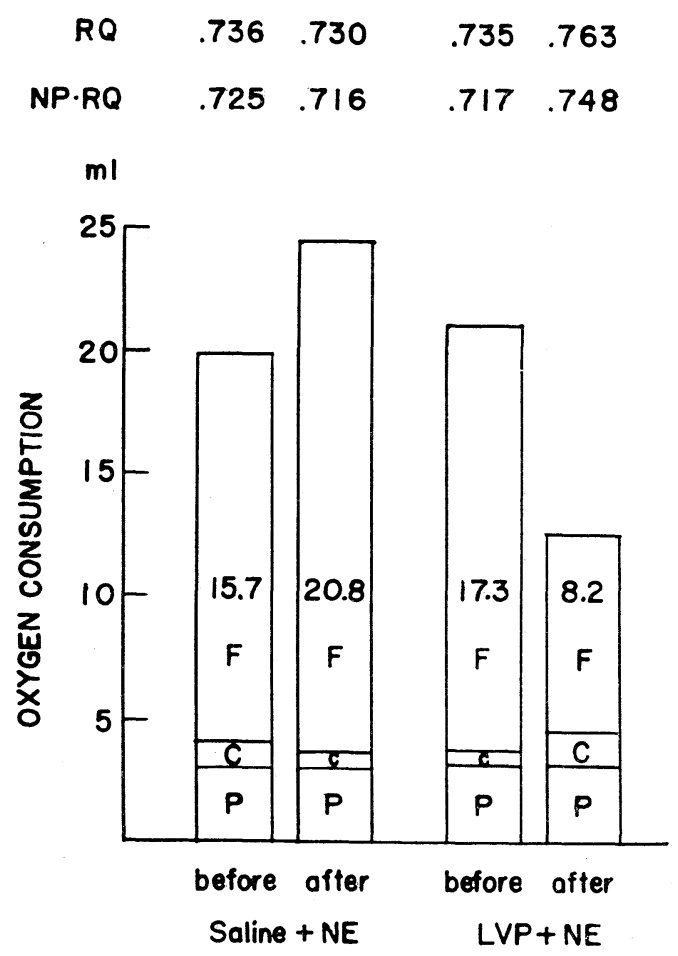

FIG. 3. Changes in the proportion of fat oxidation following norepinephrine injection with or without vasopressin treatment in fasted rats.

NP.RQ : non-protein RQ, F : fat, $C$ : carbohydrate, $P$ : protein

effect on fat utilization. Further experiments are now in progress to demonstrate direct evidence of the vasopressin effect on fat metabolism.

\section{SUMMARY}

1. The administration of synthetic lysine vasopressin (100 and $40 \mathrm{mU}$ per $100 \mathrm{~g}$, i. p.) caused a marked decrease in the metabolic rate in fasted rats. Synthetic oxytocin (400 mU per $100 \mathrm{~g}$, i. p.) had no effect.

2. The administration of hypertonic sodium chloride solution ( $2 \mathrm{ml}$ per $100 \mathrm{~g}$, per os) caused a slight but significant decrease in the metabolic rate in fasted rats. Chronic administration of 2 per cent sodium chloride solution for 7 days did not show any change in the metabolic rate.

3. In sugar administered rats the decrease in the oxygen consumption produced by vasopressin was associated with an elevation of the RQ. In rats with high $R Q$ values exceeding 0.900 the suppressive effect of vasopressin was not observed. 
4. The calorigenic effect of norepinephrine was entirely abolished by treatment with vasopressin.

5. In alloxan diabetic rats the suppressive effect of vasopressin was also observed, though the metabolic rate was extremely low in these animals.

6. The results suggest that vasopressin exhibits its effect on the metabolic rate by suppressing fat utilization as metabolic fuel.

This investigation was supported by the U.S. Department of Army through its Far East Office and in part by the research aid of the Ministry of Education, Japan.

\section{REFERENCES}

1) Okuno, A., M. Yamamoto and S. Itoh: Lowering of the body temperature induced by vasopressin. Jap. J. Physiol. (in press)

2) Steinberg, D., P. J. Nestel, E.R. Buskirk and R.H. Thompson: Calorigenic effect of norepinephrine correlated with plasma free fatty acid turnover and oxidation. J. Clin. Invest. 43: 167-176, 1964.

3) Bergen, S.S., Jr., R. Sullivan, J.G. Hilton, S. W. Willis, Jr. and T. B. Van Itallie: Glycogenolytic effect of vasopressin in the canine liver. Am. J. Physiol. 199: 136-138, 1960.

4) Bergen, S.S. Jr., R. Sullivan and J.G. Hilton: Hepatic glycogenolytic effect of vasopressin. Feder. Proc. 19: 81, 1960.

5) CASH, W.D. AND M.H. KAPLAN: A comparison of the effects of 8-lysine-vasopressin, 1-deamino-8-lysine-vasopressin and 1-acetyl-8-lysine-vasopressin on the blood glucose level in rabbits. Endocrinology 74:803-804, 1964.

6) Mirsky, I. A.: Relative effect of insulin, oxytocin, and vasopressin on the free fatty acid concentration of the plasma of nondiabetic and diabetic dog. Endocrinology 73: 613-618, 1963.

7) Mirsky, I. A.: Effect of oxytocin, vasopressin, and related peptides on plasma free fatty acids. Am. J. Physiol. 204: 842-846, 1963.

8) Thibault, O.: Adrénaline et sympathine. Action de la noradrénaline sur la consommation d'oxygène du Rat blanc. C. r. Soc. Biol. Paris 142: 47-50, 1948.

9) Fredrickson, D.S. And R.S. Gordon, Jr.: Transport of fatty acids. Physiol. Rev. 38: 585-630, 1958.

10) Hannon, J.P. AND A.M. LARson: Fatty acid metabolism during norepinephrineinduced thermogenesis in the cold-acclimatized rat. Am. J. Physiol. 203: 1055-1061, 1962. 